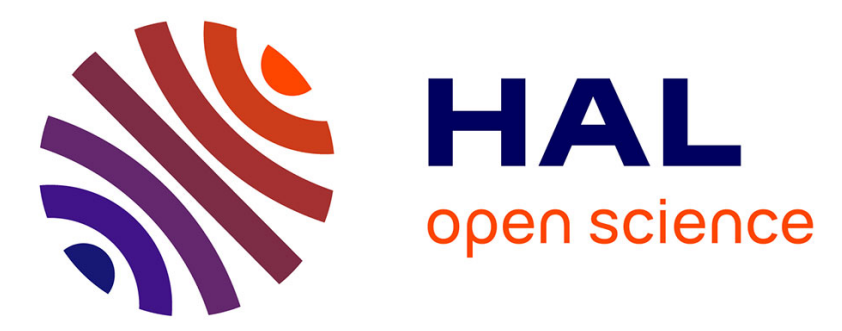

\title{
Design of an integrated quality-assurance strategy in production systems
}

Daria Battini, Maurizio Faccio, Alessandro Persona, Fabio Sgarbossa

\section{To cite this version:}

Daria Battini, Maurizio Faccio, Alessandro Persona, Fabio Sgarbossa. Design of an integrated qualityassurance strategy in production systems. International Journal of Production Research, 2011, pp.1. 10.1080/00207543.2011.555428 . hal-00717971

\section{HAL Id: hal-00717971 \\ https://hal.science/hal-00717971}

Submitted on 15 Jul 2012

HAL is a multi-disciplinary open access archive for the deposit and dissemination of scientific research documents, whether they are published or not. The documents may come from teaching and research institutions in France or abroad, or from public or private research centers.
L'archive ouverte pluridisciplinaire HAL, est destinée au dépôt et à la diffusion de documents scientifiques de niveau recherche, publiés ou non, émanant des établissements d'enseignement et de recherche français ou étrangers, des laboratoires publics ou privés. 


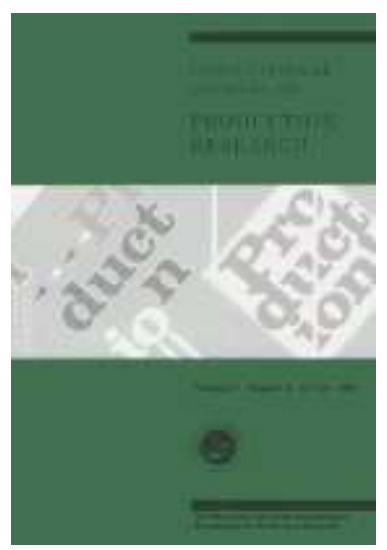

\section{Design of an integrated quality-assurance strategy in production systems}

\begin{tabular}{|r|l|}
\hline Journal: & International Journal of Production Research \\
\hline Manuscript ID: & TPRS-2010-IJPR-0670.R1 \\
\hline Manuscript Type: & Original Manuscript \\
\hline Date Submitted by the & 21 -Oct-2010 \\
\hline Complete List of Authors: & $\begin{array}{l}\text { Battini, Daria; University of Padova, Dpt. Management and } \\
\text { Engineering } \\
\text { Faccio, Maurizio; University of Padova, Dpt. Innovation in } \\
\text { Mechanics and Management } \\
\text { Persona, Alessandro; University of Padova, Dpt. Management and } \\
\text { Engineering } \\
\text { Sgarbossa, Fabio; University of Padova, Dpt. Management and } \\
\text { Engineering }\end{array}$ \\
\hline Keywords: & \begin{tabular}{l} 
PRODUCTION MANAGEMENT, QUALITY ASSURANCE \\
\hline Keywords (user):
\end{tabular} \\
\hline
\end{tabular}

\section{SCHOLARONE"}

Manuscripts 


\title{
Design of an integrated quality-assurance strategy in production systems
}

\author{
Daria Battini
}

Department of Management and Engineering, University of Padua, Vicenza, Italy

Stradella San Nicola, 3

36100 Vicenza, Italy

Phone: 00390444998735

Fax: 00390444998884

Mail: daria.battini@unipd.it

Maurizio Faccio

Department of Innovation in Mechanics and Management, University of Padua, Padova, Italy

Via Venezia, 1

35131 Padova, Italy

Phone: 00390498276796

Fax: 00390498276816

Mail: maurizio.faccio@unipd.it

\author{
Alessandro Persona \\ Department of Management and Engineering, University of Padua, Vicenza, Italy \\ Stradella San Nicola, 3 \\ 36100 Vicenza, Italy \\ Phone: 00390444998745 \\ Fax: 00390444998884 \\ Mail: alessandro.persona@unipd.it \\ Fabio Sgarbossa $\dagger$ \\ Department of Management and Engineering, University of Padua, Vicenza, Italy \\ Stradella San Nicola, 3 \\ 36100 Vicenza, Italy \\ Phone: 00390444998735 \\ Fax: 00390444998884 \\ Mail: fabio.sgarbossa@unipd.it \\ $\dagger$ corresponding author \\ (Received XX Month Year; final version received XX Month Year)
}




\begin{abstract}
High-quality of products is a critical issue for manufacturers to maintain their competitiveness in global markets. For this reason, more attention has been paid by operations managers and academics about the design of quality-assurance strategies, acceptance sampling plans and inspection allocation problems. In the last decades, international research has studied and introduced several models and approaches to investigate these issues.

The purpose of this paper is to provide a new methodology for designing and selecting correct integrated quality-assurance strategies, defining cost models for acceptance policies and inspection station configurations.

Generally, high-quality of items is guaranteed avoiding defects, mainly caused by nonconforming components, due to instantaneous and standard infant mortality. Thus, the optimal acceptance policy is defined in order to reduce the instantaneous infant mortality defects. A close formulation has been introduced to determine easily and quickly the optimal percentage of checked items. Furthermore, the more convenient inspection station configuration is determined in order to minimize the expected total cost, composed by testing, inspection and penalty cost elements. The innovative concept of defect rate as an inspection time variable dependent has been introduced.

The impact of different economic and survival parameters on designing inspection policies is also investigated. Finally, a real case study demonstrates the applicability of this methodology in real production systems and several considerations are reported about the future researches, that the authors will carry out.
\end{abstract}

Keywords: quality-assurance strategy, acceptance policy, inspection allocation problem, timedependent defect rate, cost models, case studies

\title{
1. Introduction and literature review
}

One of the most important problems that companies have been focusing on for the last 20-30 years is quality. The increasing competitiveness of markets lead quality to become widely regarded as a key element for success in business, especially in manufacturing industries.

From a productive point of view, quality can be defined as the fraction of goods that are produced correctly at the first time. In general terms, all production systems are technologically incapable to guarantee total quality of finished products and the main costs that occur in the after sale services for these items are typically warranty and penalty costs, linked to the infant mortality of products.

Furthermore, the extension of supply chain at global levels, such as the adoption of suppliers which production plants are placed in developing countries, in order to reduce the purchased component cost, has involved to evident reductions of quality in these items. 
From a customer satisfaction point of view, this kind of defect is unacceptable and reduces confidence in customers. They are mainly caused by defects on design and production of products and on low quality assembled or used items in finished products.

Consequently, a defect in a finished product can be caused by two kinds of fault.

The first one is the Instantaneous Infant Mortality Defect (IIMD). It occurs at time 0 when an item does not guarantee several required features. The second group of defects depends on standard infant mortality and it is called Standard Infant Mortality Defect (SIMD). The correct acceptance policy permits to detect first type of defects (IIMD), defining how and how many items have to be checked during the acceptance phase, typically with on-off tests.

Then, the right inspection station configuration allows to find defects belonging to the second group of defects (SIMD). Generally, the objective of inspection is to detect defective items as soon as possible and then to formulate appropriate treatments. As a consequence, one of the problem is to choose the locations to insert inspection stations inside production systems, which defects can be found during the testing and how defected items have to be treated.

Thus, it has become more and more important to define an high effective qualityassurance strategy, establishing the correct mix of acceptance policies on purchased items and on inspection station configurations in the production systems, in order to minimize the total quality cost of analyzed production system.

In the last decades, many research efforts have been conducted to study the quality of components and finished products in different production systems and to evaluate its effects in the production costs and performance (Battini et al., 2007, 2008, 2009a, 2009b, 2009c, Persona et al., 2007, 2009). 
High quality of products required by customers has involved in definition of qualityassurance strategy. General surveys on this problem have been introduced by Raz (1986) and well completed by the more recent work of Mandroli, Shrivastava, and Ding (2006).

According to this latter research, the quality-assurance strategy has the aim to allocate the economically appropriate level of inspection activities, between acceptance policies and inspection allocation configuration, balancing the various cost components of inspection, repair, replacement due to detection tasks and the warranty penalty when a defective product reaches the customer.

Consequently, the main questions that an operations manager has to solve regard how many purchased the components have to be checked and where should the inspection station be allocated inside the production system, in order to guarantee high-quality levels at lower costs.

\subsection{Contributions on acceptance policy}

One of the elements that has to be optimized is the acceptance policy on purchased components in order to minimize the introduction of nonconforming items in production systems, reducing the cost of defective finished products.

Different acceptance policies are used in manufacturing control strategy, depending on category of items, production systems, final markets and others.

Often, one of these is the $100 \%$ inspection of items. In this case, checking all items brings to a high total inspection cost but no penalty cost due to the scrap or replacement of all defective items.

Viceversa, using no inspection policy, as acceptance strategy, permits to eliminate the inspection cost but increases the penalty one due to all the defective products that were not eliminated from the production system. 
Another frequent policy is the acceptance sampling, where only a percentage of total items is checked. Dodge and Romig (1959) were the first ones to develop and introduce the inspection tables to define the right acceptance sampling. This study was originally applied by the U.S. military to the test bullets during World War II. If every bullet were tested in advance, no bullet would be left to ship. On the other hand, if none were tested, malfunctions might occur in the battlefield with potentially disastrous results (Military Standard 105E, 1989).

International Normative has been introduced to give guidance for acceptance sampling of products, during the last years. Since these standards do not take quality cost directly into account, the economic aspect of this issue has been widely investigated by international researchers, in several books and scientific papers (Montgomery, 2001).

In Tagaras (2001), a section is dedicated to the economic evaluation of acceptance sampling plans while more detailed information has been treated in Hald (1981).

Relevant surveys about the contributions on this field have been written by Wetherrill and Chiu (1975) and by Wall and Elshennawy (1989), giving extensive references to economically optimum sampling strategies.

In particular, several studies have examined the problem using linear cost models and others using Bayesan or Taguchi approaches (Barad, 1986, Case and Bennet, 1977, Chen et al., 2004a, 2004b, Ferrell and Choker, 2002, Gonzalez and Palomo, 2003, Lee and Tagaras, 1992, Malakooti and Balhorn, 1987, Tagaras and Lee, 1987).

An interesting research has been carried out by Nikolaidis and Nenes (2009), where they have evaluated the cost of implementation of single-sampling plans by attributes that are recommended by normative and then compared it against the respective cost of the optimum acceptance sampling plans. 


\subsection{Contributions on inspection allocation policy}

An extensive literature has been developed in the last decades about designing the right assurance-quality strategy, regarding the inspection allocation problem, especially the definition of correct inspection station configuration.

The introduction of inspection stations in a production system is an additional cost. At the same time, it is a profitable action because of benefits gained by the anticipating detection of defective items during the production process, avoiding the advancing on the production systems of nonconforming items and finally the sales of low-quality finished products.

Lindsay and Bishop (1964) have first studied the inspection allocation problem policy, introducing a general total cost, composed by inspection and scrap costs. They have applied a computational procedure based on dynamic programming to solve the problem.

Other researchers have investigated the problem also including other costs, like diagnosis and repair cost, loss resulting from removal of a unit perceived to be nonconforming less any applicable salvage value and penalty associated with shipping a nonconforming unit (Kakade et al., 2004, Lee and Unnikrishnan, 1998, Rau et al., 2005, Shiau, 2002). Viswanadham, Sharma and Taneja (1996) have studied dynamic and integer programming methods, using genetic algorithms and simulated annealing. Bai and Yun (1996) have introduced an inspection effort allocation model for a serial multi-stage production system, characterized by a limited number of inspection machines and by the constrain between rate of inspection and production. They have proposed a heuristic allocation algorithm using dynamic programming. Rau and Chu (2005) have considered inspection allocation problems for serial production systems with different types of workstations and different possibilities to treat detected 
nonconforming units. A profit model has been developed and a heuristic solution method has been introduced. Other researchers have addressed the problem of performance analysis in the presence of inspections (Narahari and Khan, 1996). The interest has been in investigating the effect of inspections on performance, like throughput rate, in different manufacturing systems.

\subsection{Structure of research}

After this introduction and the extensive literature review, this paper is based on the methodology used for the research and organized as follows. Section 2 will introduce the scope of research, covering the lack of international scientific contributions and giving a general methodology to design an integrated approach to assurance-quality strategy. Section 3 will explain the general assumptions and characteristics of proposed methodology and then the subsections 3.1 and 3.2 will introduce and investigate the cost models for the acceptance policy and the inspection allocation configurations.

Section 4 will introduce a real case application and finally in section 5 , general discussions and conclusions will highlight the relevance of this research and introduce further future works.

\section{Scope of Research}

The analysis of international scientific contributions has demonstrated that it is important to consider both the aspects of acceptance policy and inspection station configuration, during the design of quality-assurance policy, but no research has developed an integrated approach, yet. 
Therefore, the purpose of this research is to design an integrated quality-assurance strategy that includes both the optimization of acceptance policy and the correct inspection station configuration.

Particularly, due to the insufficient adoption of international normatives, this research introduces a new model to estimate the percentage of items to be checked based on some elements described here below, such as inspection unit cost and unit penalty cost.

Furthermore, an innovative cost model for inspection station configuration has been developed in order to consider also the probability to detect defective items as a time dependent variable. In fact, as raised from the literature review, all the contributions use a constant or random value to model the defect rate of each inspection (Mandroli, Shrivastava and Ding, 2006).

In detail, the developed methodology permits to improve the quality of products more than the previous ones, considering these important aspects:

- Integrating Approach: Total quality of products is considered, including also IIMD and SIMD, while no contribution has studied it, yet. This integrated approach allows to reach better quality results because it takes into consideration all kinds of defect, minimizing related total cost model.

- Acceptance Policy: Regarding IIMD and acceptance policy, the proposed methodology developed a cost model, based on real application and industrial requirements, while International Normative does not consider economic impacts of acceptance policy. Only Nikolaidis and Nenes (2009) have introduced a cost evaluation of simple-sampling policy. The proposed model simplifies the application of decision making process in acceptance sampling, with several assumptions explained in the next section. 
- Inspection Station Configuration: As well defined in Mandroli, Shrivastava and Ding (2006), defect rate is the quantity of defective items manufactured by a process at a station. Consequently, the inspection station configuration is defined using different defect rates. Some authors have assumed a known constant defect rate, while others have used random rate approach. As resulted by this literature overview, no research has studied the inspection station configuration using a time-dependent defect rate, while the proposed methodology permits to include this aspect into the quality-assurance policy definition. In fact, the defect rate depends on SIMD, and the occurring probability of this kind of defect is function of time, as well shown in typical bathtub curve of failure rate. Therefore, it is very important to consider the time-dependent defect rate in order to define the optimal inspection time, guaranteeing a certain quality level. In the model proposed in the following sections, the general assumption is that non-conforming items detected during inspection activities are subjected to infant mortality failure modes, described by Weibull distribution estimated by the occurred failures.

In the next sections, several total cost models has been introduced and for each cost element an extensive discussion has been done.

Several scenarios of acceptance sampling and configurations of allocation of inspection stations are studied and compared each other. The more convenient design is defined with the proposed model, considering several aspects, such as total defective percentage and unit cost elements.

\section{Cost models for quality-assurance strategy definition}

Usually, operations managers try to increase the quality level of production systems which they manage, for the above mentioned reasons. 
Figure 1 shows a general procedure to follow in order to design an optimal qualityassurance strategy. This procedure has been developed from the authors' experience and with the help of several relevant operations managers.

$* * * * * * * * * *$

Please Insert Here Figure 1.

$* * * * * * * * * *$

During Phase 1, Data Collection about defective finished products is often carried out to understand the main causes of faults and to define the more efficient improvement actions, typically using a Pareto Analysis, to reduce the infant mortality failures. The main causes of low quality are defined with a Failure Analysis and usually they are related to the wrong design and imperfect production and to low quality of manufactured or used items in finished products.

Consequently, continuing the definitions introduced before, the principal causes of defects, which are subjected to quality-assurance strategy, can be listed into two groups (Defect Classification):

- Instantaneous Infant Mortality Defect (IIMD), that is when an item does not work at time 0 or when it has not several required features, such as particular geometric dimensions or fixed electrical characteristics. The impact of this type of defect on quality of finished products can be reduced using the appropriate acceptance policy.

- Standard Infant Mortality Defect (SIMD), that is when an item does not work properly at the first times of its life, normally in the first minutes, such as material defects, design blunders, errors in assembly and production process. 
Typical examples of SIMD are fails in electronic components, like mainboards for command of mechatronic systems, or defects in mechanical components, such as die-casting items with cracks due to wrong cooling process. The introduction of inspection stations in production systems permits to increase the quality, maintaining low total costs.

Therefore, in Phase 2, it is necessary to apply a cost model for the acceptance policy, optimizing the percentage of items to check, based on inspection and penalty unit costs, and a cost model to evaluate the different inspection stations configurations, based on time-dependent defect rates.

Finally in Phase 3, the operations managers can define the optimal quality-assurance strategy combining the results of previous phase.

In the next subsections, the mathematical models will introduce and discuss the two aspects of quality-assurance strategy, while methodologies for Phase 1 of this procedure will not be treated in this paper and it will make reference to the classical approaches presented in literature and in practice.

\subsection{Acceptance Policy - Mathematical Definition and Discussions}

The IIMDs are one of the causes of defective finished products. The qualityassurance strategy have to guarantee high quality levels, also avoiding the introduction of defective purchased components in finished products.

An Expected Total Acceptance Cost (ETAC) is modeled in order to consider both the inspection cost and penalty cost. Minimizing this cost function, the acceptance policy defines the percentage of items to check.

As introduced in literature review, there are many cost models for the acceptance sampling all based on international normative and on Bayesian or Taguchi methodologies. 
In this research, a particular simplified model has been developed and introduced in order to extend its application in many manufacturing systems and to simplify the use of this model. The introduction of very simple close analytical formulations allows the wide use of this model and its application in real cases because of the introduced cost elements and quality parameters are typically known for operations and quality managers. If an operations manager uses the normative for acceptance sampling, please refer to Nikolaidis and Nenes research (2009).

However, this model is based on the Nikolaidis and Nenes research (2009) using the following assumptions in order to define the cost functions, burnt from the experience of the authors and interviewing several operations managers:

- A fixed percentage of items is checked at the acceptance station.

- Each defective component found during the control is replaced by the supplier.

- The supplier pays the cost of items replacement.

- The defective items not checked by the initial control can be presented during the production process or after sale.

- The percentages of defective items on the different situations are known.

- In the case of a defect in production process or after sale, all the same components are submitted to $100 \%$ inspection.

The Expected Total Acceptance Cost (ETAC) [€/item] is defined as the sum of two elements, the Check Cost (CC) and the Penalty Cost (PC), see formula 1:

$\mathbf{E T A C}=\mathrm{CC}+\mathrm{PC}$

Defining $\mathbf{x}$ as the percentage of checked items and $\mathbf{C}_{\mathbf{u} \boldsymbol{\varepsilon}}$ as the unit control cost [€/item], the Control Cost (CC) is then defined as follows: 
$\mathrm{CC}=\mathrm{x} * \mathrm{C}_{\mathrm{we}}$

While the Penalty Cost (PC) is proportional function of sample $(1-\mathbf{x})$. In fact, this percentage of items is inserted into the production system. Under this assumption, every defected item, belonging to this sample, could either be found during the manufacturing stages or reach the customer. When a defected item is found, all the sample $(1-\mathbf{x})$ has been checked.

Under these statements, the total Penalty Cost can be expressed by the sum of different terms as following:

$\mathbf{P C}=\mathrm{s} *(1-\mathrm{x}) *\left[\mathrm{CC}_{\mathrm{p}}+\mathrm{CC}_{0}+\mathrm{PC}_{\mathrm{p}}+\mathrm{PC}_{\mathrm{o}}+\mathrm{C}_{\mathrm{m}}\right]$

where:

$\mathbf{s}$ = maximum percentage of defective components, that depends on the supplier and typically its value is between $0 \%$ and $6 \%$;

$\mathbf{C C}_{\mathbf{p}}=$ Check Cost of entire sample $(1-\mathbf{x})$ when a defect is found during the production process;

$\mathbf{C C}_{\mathbf{c}}=$ Check Cost of entire sample $(1-\mathbf{x})$ when a defect is found after sale by the customer;

$\mathbf{P C}_{\mathbf{p}}=$ Penalty Cost when a defect is found during the production process;

$\mathbf{P C}_{\mathbf{c}}=$ Penalty Cost when a defect is found after sale by the customer;

$\mathbf{C}_{\mathbf{m}}=$ management cost due to stocking, replacing, recalling and other management activities [€/item].

In detail, each term is defined by the following extended equations:

$$
\begin{aligned}
& \mathrm{CC}_{\mathrm{p}}=\left[\mathrm{C}_{\mathrm{uc}}^{f} * \mathrm{NC}_{\mathrm{p}} *(1-\mathrm{x})\right] \\
& \mathrm{CC}_{\mathrm{c}}=\left[\mathrm{C}_{\mathrm{uC}}^{\prime} * \mathrm{NC}_{\mathrm{c}} *(1-\mathrm{x})\right] \\
& \mathrm{PC}_{\mathrm{p}}=\mathrm{C}_{\mathrm{p}}^{f} * \mathrm{NC}_{\mathrm{p}}
\end{aligned}
$$


$\mathbf{P C}_{0}=\mathrm{C}^{r_{g}} \neq \mathrm{NC}_{0}$

where:

$\mathbf{C}_{\mathbf{u c}}^{s}=$ unit control cost when a defect is found during the production process [€/item];

$\mathbf{C}_{\text {uc }}^{8 B}=$ unit control cost when a defect is found after sale by the customer [€/item];

$\mathbf{N C}_{\mathbf{p}}=$ percentage of defective items occurred during the production process;

$\mathbb{N C}_{\mathbf{c}}=$ percentage of defective items occurred after sale by the customer (note that:

$\mathrm{NC}_{\mathrm{p}}+\mathrm{NC}_{\mathrm{c}}=1$

$\mathbf{C}_{\mathrm{p}}^{8}=$ penalty cost due to the defective items appeared during the production [€/item];

$\mathbf{C}^{n}{ }_{\mathrm{p}}=$ penalty cost due to the defective items appeared after sale by the customer

[€/item];

$\mathbf{C}_{\mathbf{m}}=$ management cost due to stocking, replacing, recalling and other management activities $[€ /$ item].

As a consequence, the extended Penalty Cost formulation is:

$\mathbf{P C}=\mathbf{s} *(\mathbf{1}-\mathbf{x}) *\left\{\left[\mathrm{C}_{\mathrm{ue}}^{g} * \mathrm{NC}_{\mathrm{p}} *(\mathbf{1}-\mathbf{x})\right]+\left[\mathrm{C}_{\mathrm{ue}}^{p} * \mathrm{NC}_{\mathrm{e}} *(\mathbf{1}-\mathbf{x})\right]+\mathrm{C}_{\mathrm{p}}^{p} * \mathrm{NC}_{\mathrm{p}}+\mathrm{C}_{\mathrm{p}}^{p} * \mathrm{NC}_{\mathrm{e}}+\mathbf{C}_{\mathrm{m}}\right\}$

Using the previous formulations, the ETAC can be rewritten as follows:

$\mathbf{E T A C}=\mathbf{x} * \mathrm{C}_{\mathrm{uc}}+\mathbf{s} *(\mathbf{1}-\mathbf{x}) *\left\{\left[\mathrm{C}_{\mathrm{uc}}^{\prime} * \mathrm{NC}_{\mathrm{p}} *(\mathbf{1}-\mathbf{x})\right]+\left[\mathrm{C}_{\mathrm{uc}}^{\prime \prime} * \mathrm{NC} \mathrm{C}_{\mathrm{c}} *(\mathbf{1}-\mathbf{x})\right]+\mathbf{C}_{\mathrm{p}}^{x} * \mathrm{NC}_{\mathrm{p}}+\mathrm{C}_{\mathrm{p}}^{\mathrm{x}} * \mathrm{NC}_{\mathrm{c}}+\mathrm{C}_{\mathrm{m}}\right.$ [9]

Minimizing this total cost function over $\mathbf{x}$, in order to find the optimal value of percentage of items to check:

\section{$\frac{\partial \mathbf{E T A C}}{\partial \mathrm{x}}=0$}

$\frac{\partial \mathrm{ETAC}}{\partial \mathrm{x}}=\mathrm{C}_{\mathrm{uc}}-\mathbf{s} *(1-\mathrm{x}) *\left\{\left[\mathrm{C}_{\mathrm{uc}}^{\prime} * \mathrm{NC}_{\mathrm{p}} *(1-\mathrm{x})\right]+\left[\mathrm{C}_{\mathrm{uc}}^{\prime \prime} * \mathrm{NC}_{\mathrm{o}} *(1-\mathrm{x})\right]+\mathrm{C}_{\mathrm{p}}^{\prime} * \mathrm{NC}_{\mathrm{p}}+\mathrm{C}_{\mathrm{p}}^{* *} * \mathrm{NC}_{\mathrm{a}}+\mathrm{C}_{\mathrm{m}}\right\}=$ [11] 
After several mathematical steps, the optimal value of $\mathbf{x}$, called $\mathbf{x}^{*}$ is defined by this close expression:

$$
x^{*}=1-\frac{\mathrm{C}_{\mathrm{uc}}-\mathrm{s} *\left(\mathrm{C}_{\mathrm{p}}^{\prime} * \mathrm{NC}_{\mathrm{p}}+\mathrm{C}^{\prime \prime}{ }_{\mathrm{p}} * \mathrm{NC}_{\mathrm{c}}+\mathrm{C}_{\mathrm{m}}\right)}{2 * \mathrm{~s} *\left(\mathrm{C}_{\mathrm{uc}}^{\prime} * \mathrm{NC}_{\mathrm{p}}+\mathrm{C}_{\mathrm{uc}}^{\prime \prime} * \mathrm{NC}_{\mathrm{c}}\right)}
$$

Considering the application constraints, these particular cases have to be considered on formula [12]:

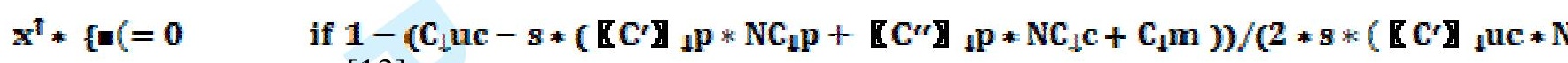

Using this formula, the operations managers can easily determine the optimal percentage of item to check during the acceptance phase, after having estimated the unit costs and defective parameters.

\section{General Considerations and Numerical Examples}

The introduction of several general parameters can simplify the application of this model as follows.

Defining $\mathbf{C}_{\mathrm{APT}}$ as the average penalty total cost using the following equation:

$$
\mathrm{C}_{\mathrm{APT}}=\mathrm{C}_{\mathrm{p}}^{r} * \mathrm{NC}_{\mathrm{p}}+\mathrm{C}_{\mathrm{p}}^{s r} * \mathrm{NC}_{\mathrm{c}}+\mathrm{C}_{\mathrm{m}}
$$

and $\mathbf{C}_{\mathrm{ucNC}}$ as the unit control cost for nonconforming item occurred during production process or after sale, with the following formulation:

$$
\mathrm{C}_{\mathrm{uNC}}=\mathrm{C}_{\mathrm{ue}}^{\prime} * \mathrm{NC}_{\mathrm{p}}+\mathrm{C}_{\text {ue }}^{s r} * \mathrm{NC}_{\mathrm{a}}
$$


then, the optimal value of percentage to check, $\mathbf{x}^{*}$ can be calculated using the simple formulas, considering the application constraints:

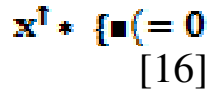

The proposed model to estimate the expected total cost for the acceptance policy (ETAC) is here discussed with several numerical examples and its behavior is investigated in order to give general guide lines for the practitioners.

Table 1 contains the parameters used in the examples, estimating the typical values occurred in real applications, and figure 2 shows the ETAC function, over the percentage $\mathbf{x}$, for scenario 1 .

\section{$* * * * * * * * * *$ \\ Please Insert Here Table 1. \\ $* * * * * * * * * *$ \\ $* * * * * * * * * *$ \\ Please Insert Here Figure 2.}

Observing formula [16], the optimal value $\mathbf{x}^{*}$ is function of four simple parameters and its behavior is strictly linked to these as follows:

- the optimal value is directly proportional to parameters $s, C_{A P T}$ and $C_{u C N C}$; 
- while it is inversely proportional only to parameter $C_{u c}$.

\subsection{Inspection Allocation Configuration - Mathematical Definition and \\ Discussions}

To guarantee high-quality on finished products, the definition of correct inspection station policy is necessary to reduce the defective products due to SIMDs. The prompt detection of defective items is the main goal of the inspection policy.

A typical inspection activity is the electronic testing for several seconds or minutes of electronic components, such as resistance, main-board, embedded circuit and electric motors. During this phase, several electronic characteristics are measured and compared with the required ones in order to reject the defected items.

Another usual inspection activity is the functioning testing inside production or assembly process, where the operating of mechanical components is checked in order to identify production or assembly defects, such as wrong mechanical coupling or previous errors in assembly/production tasks. Typical examples are driving or control mechanisms, subjected to functioning testing, and fastening systems, under fixing evaluation checking.

The introduction of inspection stations in a production system generates an additional cost but it permits to reduce the penalty costs raised at the end of the process. If a product is inspected at the final step of production process, the penalty cost is higher. To adopt a strategy of inspection, reworking or scrapping at intermediate steps could reduce the penalty cost but increase considerably the inspection costs. Thus, the objective is to determine the optimal inspection station configuration in order to minimize the Expected Total Inspection Cost (ETIC). 
As discussed in literature review sections, there are many contributions about the design of inspection station configuration with an economic point of view.

The here proposed model defines the defect rate of each inspection station as a timedependent variable, while until now, the scientific contributions consider it as a constant or random value (Mandroli, Shrivastava and Ding, 2006).

Due to the small time of inspection activities, the identified failures are typical of infant mortality behaviors. Generally, components and products are subjected to a decreasing hazard rate in the early period of their lives. Consequently, the efficiency of an inspection is strictly connected to the time of inspection and to the reliability behavior of tested components. Different statistical distribution can be used to model the failure rate. In this paper, Weibull distribution is used because of its flexibility and ease. General extensions of this distribution could be introduced considering also the environmental conditions (Battini et al., 2007, 2008, Persona et al., 2009). The probability of detecting nonconforming items increases for increasing inspection time, while the probability that a defective product reaches a customer decreases, following the Weibull distribution.

Furthermore, the present model would simplify the design of inspection station policy using several useful parameters. In fact, from the analysis of literature, the contributions developed in the last decades have introduced many complex models, with few and limited real applications.

Here, several inspection stations configurations are compared each other in order to define the more convenient one. Usually, operations managers have limited and known number of configurations due to technological constraints, for example the use of complex test machines. For each inspection station, it is known which are the 
defects that can be found, assuming them statistically independent, and using the failures frequency analysis also the probability over inspection time to find a defect. Starting with these assumptions, the inspection station configurations described by the models are the following:

- In-Line Inspection Configuration: the inspection activities are completed inside the production systems, directly on the components or produced items, which have to be tested. In this case, the failure is strictly linked to the components or produced items. All the found defective items are scrapped and replaced with an additional unit cost (fig. 3).

- Final Inspection Configuration: in this case, there is a unique inspection station at the end of the production system that tests the functioning of finished products. In this case, it is difficult to define the cause of the failures and which component or produced items is defective. Consequently, the unit cost of failure detection is bigger than the previous case (fig. 3).

$* * * * * * * * * *$

Please Insert Here Figure 3.

The mathematical formulations of models for each configuration are now introduced and discussed. A list of notations is here reported in order to understand the mathematical formulations.

\section{Notations}

Indices

$\boldsymbol{i}=$ In-Line inspection station index; 
$a=$ Final inspection station index;
$n=$ number of inspection stations;

\section{Time parameters}

$\mathbf{t}_{i}^{c}=$ inspection time at station $i$

$\boldsymbol{t}_{a}^{C}=$ inspection time at final station $o$

\section{Defect parameters}

$S_{i}=$ maximum percentage of defective components or produced items that can be detected at station $i$; it is the percentage of defective components provided by supplier. For example $S_{i}=5 \%$ means that every 100 checked components, 5 are non conforming.

$S_{o}=$ maximum percentage of defective end products that can be detected at final station $o$, defined as follows:

$S_{o}=\left[1-\prod_{i=1}^{n}\left(1-s_{i}\right)\right]$

$S_{o}$ is the percentage of defect end-products at the end of production process. It is related to the percentage of each defective component belonging to the final product. This formula comes from statistical considerations, an end-product is conforming if all its components are conforming.

$\alpha_{i}=$ scale factor of Weibull distribution for components or pre-manufactured tested at station $i$;

$\beta_{i}=$ scale factor of Weibull distribution for components or pre-manufactured tested at station $i$ 
$\left.\mathbb{Z} F_{i}(t]_{i}^{c}\right)=$ probability that a defect occurs before time $t_{i}^{c}$ at station $i$, using Weibull formula:

$F_{i}\left(t_{i}^{c}\right)=1-e^{-\left(\frac{c_{i}}{\alpha_{i}}\right)^{\beta_{i}}}$

The detection of failure, the defect rate, follows a statistical distribution and it depends on the time spent to inspect the component. For this reason, we have introduced the defect rate as the probability that a defect occurs before a defined time. Increasing inspection time, increasing defect rate. Weibull distribution is used due to its great flexibility.

$\left.\mathbb{Z} F_{o}(t]_{o}^{c}\right)=$ probability that a defect occurs before time $t_{\sigma}^{\mathscr{C}}$ at station $o$, calculated using this formula:

$\mathbb{Z} F_{Q}\left(t_{i}^{g}\right)=\left[1-\prod_{i=1}^{n}\left(1-F_{i}\left(t_{i}^{c}\right)\right)\right]$

As assumed for formula 17, the formula 19 is derived from statistical considerations. The probability that a single defect occurs during the inspection of end-product is defined by this formula, adapting the traditional models for calculating the reliability of series systems, known the reliability of single components.

\section{Cost parameters}

$c_{i}^{u c}=$ inspection unit cost per time at station $i$

$c_{o}^{u c}=$ inspection unit cost per time at final station $o$;

$c_{i}^{u s \mathbf{1}}=$ mean unit cost for remove one defect at station $i$;

$c_{o}^{u s 1}=$ mean unit cost for remove one defect at final station $o$;

$c_{i}^{u s z}=$ mean penalty unit cost for a defect occurs after time $t_{i}^{c}$; 
$c_{\hat{n}}^{u s z}=$ mean penalty unit cost for a defect occurs after time $t_{\hat{a}}^{C}$.

\section{In-Line Inspection Configuration Cost Model}

According to the description of this inspection station allocation, introduced before, the expected total cost is the sum of the expected cost of each inspection station, then it can be defined as follows:

$E T I C_{n C}=\sum_{i=1}^{n}\left(C_{i}^{c}+C_{i}^{s 1}+C_{i}^{s 2}\right)$

where:

the expected inspection cost at station $i$ :

$c_{i}^{C}=t_{i}^{C} * c_{i}^{u C}$

expected defects removal cost at station $i$ :

$c_{i}^{\Sigma 1}=S_{i} * Z F_{i}\left(t_{i}^{C}\right) * c_{i}^{U S 1}$

Expected penalty cost of defects not removed on station $i$ :

$C_{i}^{S 2}=\mathbb{Z} S_{i} *\left(1-F_{i}\left(t_{i} g\right)\right) * c_{i}^{u g 2}$

Final Inspection Configuration Cost Model

The allocation of inspection activities at the final station can be represented by the following mathematical formulation:

$E T I C_{F I C}=C_{b}^{C}+C_{0}^{S 1}+C_{d}^{S 2}$

where:

Expected inspection cost at station $o$ :

$c_{o}^{C}=t_{o}^{c} * c_{a}^{u C}$

Expected defects removal cost at station $o$ : 
$\left.C_{0}^{S 1}=S_{0} * \mathbb{Z} F_{0}(t]_{0}^{\varepsilon}\right) * c_{0}^{u S 1}$

Expected penalty cost of defects not removed on station $o$ :

$\left.C_{0}^{S 2}=\mathbb{Z} S_{0} *\left(1-F_{0}(t]_{0}\right)\right) * c_{0}^{u s 2}$

\section{Selection of Inspection Station Policy}

Using the formulas previously defined, the selection of more convenient inspection station configuration follows these considerations:

- Select In-Line Inspection Configuration if $E C_{I I C}$ is minor than $E T I C_{F I C}$;

- Select Final Inspection Configuration if $E C_{I I C}$ is major than $E T I C_{F I C}$.

\section{General Considerations and Parameter Analysis}

The definition of defect rate here introduced by formula [18] shows the dependence on inspection time of the probability of defect detection. As our knowledge and as described in Mandroli, Shrivastava and Ding (2006), the defect rate has been defined as a constant or random value. For further readings, see the papers analyzed by (Mandroli, Shrivastava and Ding, 2006).

Furthermore, the more convenient solution of the inspection station allocation problem comes from the comparison of the results of the previous model applied to each configuration. It is important to note that in the final inspection configuration, the probability that a component fails in $t_{\delta}^{C}$ is strictly linked to the reliability behaviour of components and produced products, as described by formula [19]. At the same time, the percentage of defective end-product is function of each percentage of defective components. Moreover, the mean unit cost to remove one defect at final station $o$ is much bigger than the similar cost related to station $i$ because the 
inspection at final station checks the entire end products, as described in previous section, while the mean penalty unit costs can be the same because they do not depend on inspection station configuration.

It is important also to determine the threshold of convenience, in function of the percentage of defective items provided by supplier.

Here below an analysis of impacts of defined parameters previously is reported in order to understand their effect on specific threshold of convenience, expressed as $S^{*}$. To make comparison more general, clearer and easier to understand, several main assumptions have been taken into consideration. Each station has the same defect rate Weibull parameters, $\alpha_{i}$ and $\beta_{i}$, same maximum percentage of defective components $S_{i}$, the same inspection time $t_{i}^{c}$ and $t_{o}^{c}$, and cost parameters values, $c_{i}^{u c}$, $c_{o}^{u c}, c_{i}^{u s 2}, c_{o}^{u s 1}, \quad c_{i}^{u s 2}$ and $c_{b}^{u s z}$.

The assumed base scenario is composed by the following parameters values, included in table 2.

Figure 4 shows the threshold of convenience. The dashed curve is related to In-Line Inspection Configuration while the continued one is related to Final Station Configuration. For values lower than $S^{*}$, the more convenient configuration is the final inspection station one, while for values higher than $S^{*}$, the In-Line inspection configuration is the best choice. In this base scenario, the value of $S^{*}$ is about $3.00 \%$.

$* * * * * * * * * *$

Please Insert Here Table 2.

$* * * * * * * * * *$

$* * * * * * * * * *$ 
Please Insert Here Figure 4.

$* * * * * * * * * *$

- Firstly, the number of stations has been varied, assuming the values: 3, 5 and 7, indicated in figure respectively with "a", "b" and "c". The rest of parameters is fixed as defined in base scenario. As it can be noticed in figure 5 , the increasing of number of stations brings to an increased threshold of convenience value $S^{*}$. It is simply a consequence of the higher possibility to anticipate the defection of fault components.

\title{
$* * * * * * * * * *$
}

Please Insert Here Figure 5.

$* * * * * * * * * *$

- The second comparison has been made varying the inspection time control, assuming these values: 30 ("a"), 60 ("b") and 90 ("c") seconds. Figure 6 illustrates the three scenarios. Also in this case, the increasing of inspection time brings to an increase of $S^{*}$ value. It is well shown that the increasing of $S^{*}$ value is strictly linked to the efficiency of defection, following the Weibull distribution of defect rate.

\author{
$* * * * * * * * * *$ \\ Please Insert Here Figure 6.
}

- Then, the variation of cost parameters has been investigated. In figure 7a the inspection unit cost changes from 0.1 in the base scenario ("a") to 0.01 ("b") 
and 0.5 ("c"). In figure $7 \mathrm{~b}$, the mean unit cost to remove one defect at station $i$ has been changed from 8 of base scenario ("a") to 40 ("b") and 80 ("c"). Then, the mean unit cost to remove one defect at station $o$ assumes values as follows: 80 ("b"), 160 (base scenario - "a") and 320 (“c”), as illustrated in figure 7c. Finally, figure $7 d$ shows the comparison between base scenario, with mean penalty unit cost equal to 900 (“a”), and other scenarios with mean penalty unit costs equal to 450 ("b") and 1800 (“c”).

Generally, the increasing of inspection unit cost and mean cost to remove one defect inside the production system increases the threshold value $S^{*}$, while increasing value of mean unit cost to remove defect at final station brings to decreasing value of $S^{*}$. Finally, increasing the mean penalty cost, the threshold value increases. It is interesting to notice that, for several scenarios, the more convenient configuration is the In-Line Inspection one, for every values of maximum percentage of defective components or produced items $s_{i}$, see for example figures $7 \mathrm{~b}$ and $7 \mathrm{~d}$.

\author{
$* * * * * * * * * *$ \\ Please Insert Here Figure 7 a-b-c-d. \\ $* * * * * * * * * *$
}

- Finally, the change of Weibull shape parameter $\beta_{i}$, from the base scenario value (0.8 - "a") to two scenarios with values equal to 0.7 ("b") and 0.9 ("c") 
has been investigated (fig. 8). In this case the increasing of shape parameter value brings to the decreasing of threshold value.

\section{$* * * * * * * * * *$ \\ Please Insert Here Figure 8.}

\section{Application to a real case study}

The proposed procedure has been applied to a real case study. The manufacturing system produces a series of centrifugal pumps, such as multi-stage, standardized, for low, medium and high flows, with flanged ports. The great variability of finished products has not permitted to apply the existing approaches presented in literature due to the high complexity.

In accordance with the operations manager, the proposed models have been used to define the optimal quality-assurance strategy, because initially the production system had no policy for defects detection yet.

From the application of Phase 1 of procedure, the main IIMDs and SIMDs have been determined. The Instantaneous Infant Mortality Defects are related to two purchased components: the pump body and body backplate, where geometrical defects can occur.

While the Standard Infant Mortality Defects are functions of operating components, such as capacitors, bearings and electric motors.

For the first group of items, during Phase 2, the optimal acceptance policy has been defined using the parameters, given by the Phase 1 , and following the model here proposed. 
Table 3 reports the values of parameters necessary for the acceptance policy design.

The Expected Total Acceptance Cost values for initial scenarios, called ETAC $(0)$, have been included in order to estimate the saving of proposed model, indicated as follows:

$\triangle E T A C=\frac{E T A C(0)-E T A C\left(x^{*}\right)}{E T A C(0)}$

[28]

It is expressed in percentage value.

$* * * * * * * * * *$

Please Insert Here Table 3.

$* * * * * * * * * *$

Here below, figures 9 and 10 illustrate the curve of ETAC function for the studied components.

$* * * * * * * * * *$

Please Insert Here Figure 9. 
Please Insert Here Figure 10.

Successively, for the second type of components, a comparison between In-Line or Final Inspection Configurations is necessary. Analyzing the existing production system with the operations managers, two type of configurations can be defined, then the comparison has been done between these two situations.

The first inspection stations configuration is characterized by three inspection stations inside the production process, while the second case proposes a unique inspection station at the end of production system.

For each inspection station, from Phase 1, the Weibull parameters of inspection efficiency have been estimated using the reliability tool of Minitab@ software (fig. 11), while other parameters have been evaluated and assumed in collaboration with operations manager of production system (tables 4 and 5).

$* * * * * * * * * *$

Please Insert Here Figure 11.

$* * * * * * * * * *$

$* * * * * * * * * *$

Please Insert Here Table 4. 
Please Insert Here Table 5.

As resulted by the application of proposed models to this case, the more convenient inspection station configuration is the In-Line Inspection Configuration.

In the previous scenario, where no inspection activities have been made, the Expected Total Cost for SIMDs can be evaluated equal to $18.701 € /$ item.

The saving obtained using the proposed model is about $86 \%$, in fact the Expected Total Cost reduces its value from 18.701 to 2.595 , due to the anticipating of SIMDs detection.

Concluding, the correct quality-assurance strategy defined using the proposed models is composed by the following policies:

- Acceptance policy: inspection and check of $52.20 \%$ of Pump Body components, that permits to reduce the ETAC by $5.43 \%$;

- Acceptance policy: inspection and check of $32.40 \%$ of Body Backplate components, with the decreasing of $2.13 \%$ of ETAC;

- Inspection Station Configuration: implementation of In-Line Inspection Configuration, with three inspection stations, permits to reduce the Expected Total Cost of about $86 \%$ respect the starting scenario.

\section{Discussion and Conclusion}

In modern markets, products are required with high-quality at lower costs. For this reason, companies try to extend their supply network purchasing several 
components from developing countries in order to maintain lower costs. However, often the components bought from these suppliers have low levels of quality. Consequently, manufacturing systems need to control the quality of process and products at the lower cost, defining the optimal quality-assurance strategy, composed by acceptance policy and inspection station configuration. Several scientific contributions have studied this problem in different ways, and without an integrated approach that considers both the strategy aspects.

In this paper, a general methodology to design the correct quality-assurance strategy is introduced, defining the connection of acceptance policy and inspection allocation problem to two kind of defects: the Instantaneous Infant Mortality Defects (IIMDs) and Standard Infant Mortality Defects (SIMDs). In detail, a cost model for determining the optimal acceptance sampling is introduced in order to minimize the quality cost related to the IIMDs. A close and simple formulation has been derived in order to solve this problem. Innovative cost models have been developed to choose the more convenient inspection station configuration, defining the efficiency of inspection activities as function of inspection time. No scientific contributions has studied this aspect in inspection allocation problems. The effects of several parameters have been investigated in order to define the optimal threshold of convenience between the types of configurations.

Finally, the application on a real industrial case has shown the economic advantages of the proposed methodology.

Some limits of integrating methodologies can be listed as follows:

- Acceptance policy and inspection station configuration are supervised by different managers inside a production system, such as vendors and item 
quality managers for the first issue and operations managers for the second one.

- The difficulty to collect data from the production, therefore the need to define a correct collection data system and reliability analysis.

- The necessity to define clear cost elements to use into developed models.

- Each quality-assurance policy depends on manufactured products.

In the future, this research will try to solve these limits and the models will be extended considering also several different acceptance policies and giving general studies about the impact of parameters on more convenient configurations, as for inspection allocation problems are concerned.

\section{References}

Bai D.S. and Yun H.J., 1996. Optimal allocation of inspection effort in a serial multistage production system. Computers Industrial Engineering, 30 (3), 387-396.

Barad, M., 1986. Using break-even quality level for selecting acceptance sampling plans given a prior distribution. International Journal of Production Research, 24 (1), 65-73.

Battini D., Faccio M., Persona A., Sgarbossa F., 2007. Reliability In Random Environment: Systemability And Its Applications. In: Proceeding of ISSAT 2007 12th ISSAT International Conference on Reliability and Quality in Design. Seattle, USA. 2-4 August 2007. 
Battini D., Faccio M., Persona A., Sgarbossa F., 2008. Reliability of motorcycle components using systemability approach. In: Proceeding of ISSAT 2008 14th ISSAT International Conference on Reliability and Quality in Design, Orlando, Florida USA. 79 August 2008.

Battini D., Faccio M, Persona A., Sgarbossa F. 2009a. Design of the Optimal Feeding Policy in an Assembly System, International Journal of Production Economics, 121 (1), 233-254.

Battini D., Persona A., Regattieri A. 2009b. Buffer size design linked to reliability performance: A simulative study. Computers and Industrial Engineering, 56 (4), 16331641.

Battini D., Faccio M, Persona A., Sgarbossa F., 2009c. Balancing-Sequencing Procedure For A Mixed Model Assembly System In Case Of Finite Buffer Capacity. International Journal of Advanced Manufacturing Technology,44 (3-4), 345-359.

Case, K.E. and Bennet, G. K., 1977. The economic effect of measurement error on variables acceptance sampling. International Journal of Production Research, 15 (2), 117-129.

Chen, J. W., Chou, W., Wu, H., Zhou, H., 2004a. Designing acceptance sampling schemes for life testing with mixed censoring. Naval Research Logistics, 51 (4), 597612. 
Chen, J. W., Choy, S. T. B., Li, K. H., 2004b. Optimal Bayesian sampling acceptance plan with random censoring. European Journal of Operational Research, 155 (3), 683694.

Dodge, H. F., Romig, H. G., 1959. Sampling Inspection Tables. John Wiley, New York

Ferrell, W. G., Choker, A., 2002. Design of economically optimal acceptance sampling plans with inspection error. Computers \& Operations Research, 29 (10), 1283-1300.

Gonzalez, C., Palomo, G., 2003. Bayesian acceptance sampling plans following economic criteria: An application to paper pulp manufacturing. Journal of Applied Statistics, 30 (3), 319-333.

Hald, A., 1981. Statistical Theory of Sampling by Attributes. London: Academic Press.

Kakade, U. V., Valenzuela, J. F., Smith, J. S., 2004. An optimization model for selective inspection in serial manufacturing systems. International Journal of Production Research, 42 (18), 3891-3909.

Lee, H.L. and Tagaras, G., 1992. Economic acceptance sampling plans in complex multi-stage production systems. International Journal of Production Research, 30 (11), 2615-2632. 
Lee, J. and Unnikrishnan, S., 1998. Planning quality inspection operations in multistage manufacturing systems with inspection errors. International Journal of Production Research, 36 (1), 141-155.

Lindsay, G. F., and Bishop, A. B., 1964. Allocation of screening inspection effort Dynamic-programming approach. Management Science, 10, 343-352.

Malakooti, B. and Balhorn, W. H., 1987. Selection of acceptance sampling plans with multi-attribute defects in computer-aided quality control. International Journal of Production Research, 25 (6), 869-888.

Mandroli, S. S., Shrivastava, A. K., and Ding, Y., 2006. A survey of inspection strategy and sensor distribution studies in discrete-part manufacturing processes. IIE Transactions, 38, 309-328.

Military Standard 105E. Sampling Procedures and Tables for Inspection by Attributes. Washington D.C.: U.S.Government Printing Office (1989).

Montgomery, D.C., 2001. Introduction to Statistical Quality Control. New York: John Wiley.

Narahari, Y., \& Khan, L. M., 1996. Modeling reentrant manufacturing systems with inspection stations. Journal of Manufacturing Systems, 15, 367-378. 
Nikolaidis, Y. and Nenes, G., 2009. Economic evaluation of ISO 2859 acceptance sampling plans used with rectifying inspection of rejected lots. Quality Engineering, 21, $10-23$.

Persona, A., Regattieri, A., Pham, H., Battini, D., 2007. Remote control and maintenance outsourcing networks and its applications in supply chain management. Journal of Operation Management, 25 (6), 1275-1291.

Persona A., Pham H., Sgarbossa F., 2009. Systemability Function to Optimisation Reliability in Random Environment. International Journal of Mathematics in Operational Research, 1 (3), 397-417.

Raz, T., 1986. A survey of model for allocation inspection effort in multistage production system. Journal of Quality Technology, 18, 239-247.

Rau H. and Chu Y.-H., 2005. Inspection allocation planning with two types of workstation: WVD and WAD. International Journal of Advanced Manufacturing Technology, 25, 947-953.

Rau, H., Chu, Y.-H. and Cho, K.-H., 2005. Layer modelling for the inspection allocation problem in re-entrant production systems. International Journal of Production Research, 43 (17), 3633-3655. 
Shiau, Y-R., 2002. Inspection resource assignment in a multistage manufacturing system with an inspection error model. International Journal of Production Research, 40 (8), 1787-1806.

Tagaras, G. (2001). Statistical Quality Control. Thessaloniki: Zitis.

Tagaras, G., Lee, H. L., 1987. Optimal Bayesian single-sampling attribute plans with modified beta prior distribution. Naval Research Logistics, 34 (6), 789-801.

Wall, M. S., Elshennawy, A. K., 1989. Economically-based acceptance sampling plans. Computers \& Industrial Engineering, 17 (1-4), 340-346.

Wetherrill, G. B., Chiu, W. K., 1975. A review of acceptance sampling schemes with emphasis on the economic aspect. International Statistical Review, 43 (2), 91-210.

Viswanadham, N., Shashi, S. M., \& Taneja, M., 1996. Inspection allocation in manufacturing systems using stochastic search technique. IEEE Transactions on Systems, Man, and Cybernetics - Part A: Systems and Humans, 26, 222-230. 


\section{FIGURES CAPTIONS:}

Fig. 1: General procedure for quality-assurance strategy design

Fig. 2: ETAC function over $\mathrm{x}$ for scenario 1.

Fig. 3: In-Line vs Final Inspection Configuration

Fig. 4: Expected Total Inspection Cost (ETIC) for In-Line vs Final station configuration in function of $\mathrm{S}$

Fig. 5: Comparison of ETIC functions varying the number of station

Fig. 6: Comparison of ETIC function varying the inspection time control

Fig. 7: Comparison of ETIC function varying the cost parameters

Fig. 8: Comparison of ETIC function varying the shape parameter.

Fig. 9: ETAC function for Pump Body

Fig. 10: ETAC function for Body Backplate

Fig. 11: Defect rate in function of inspection time, for station 1, 2 and 3 (left) and final station (right). 


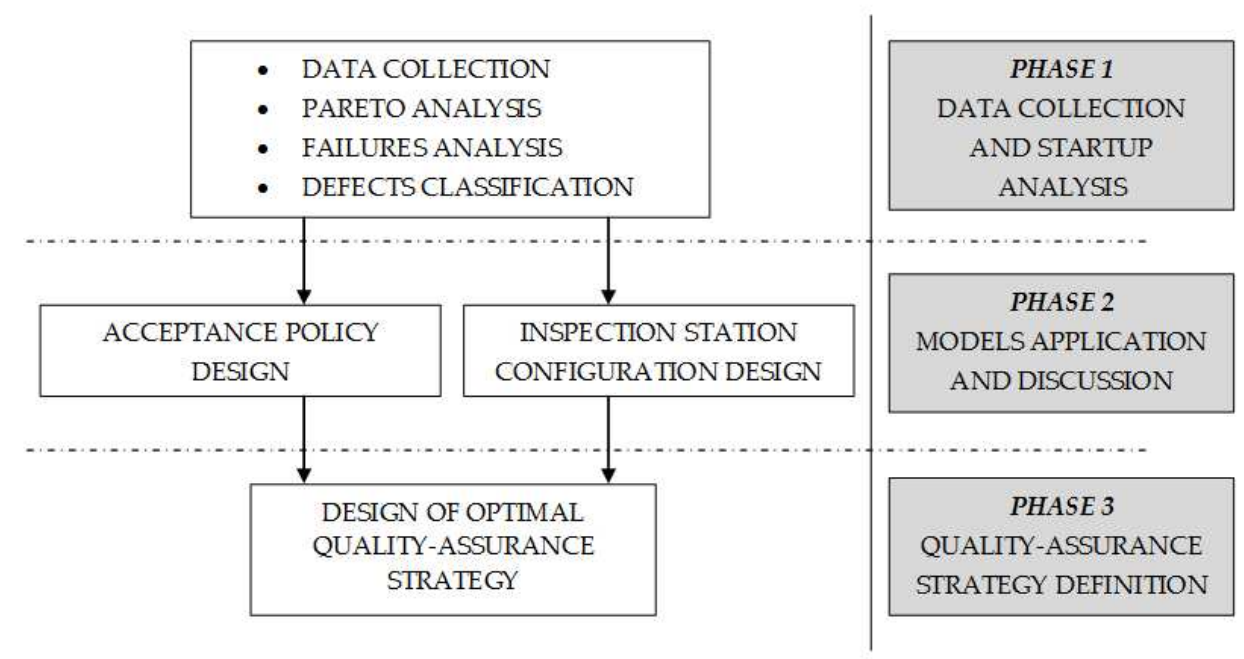

General procedure for quality-assurance strategy design 


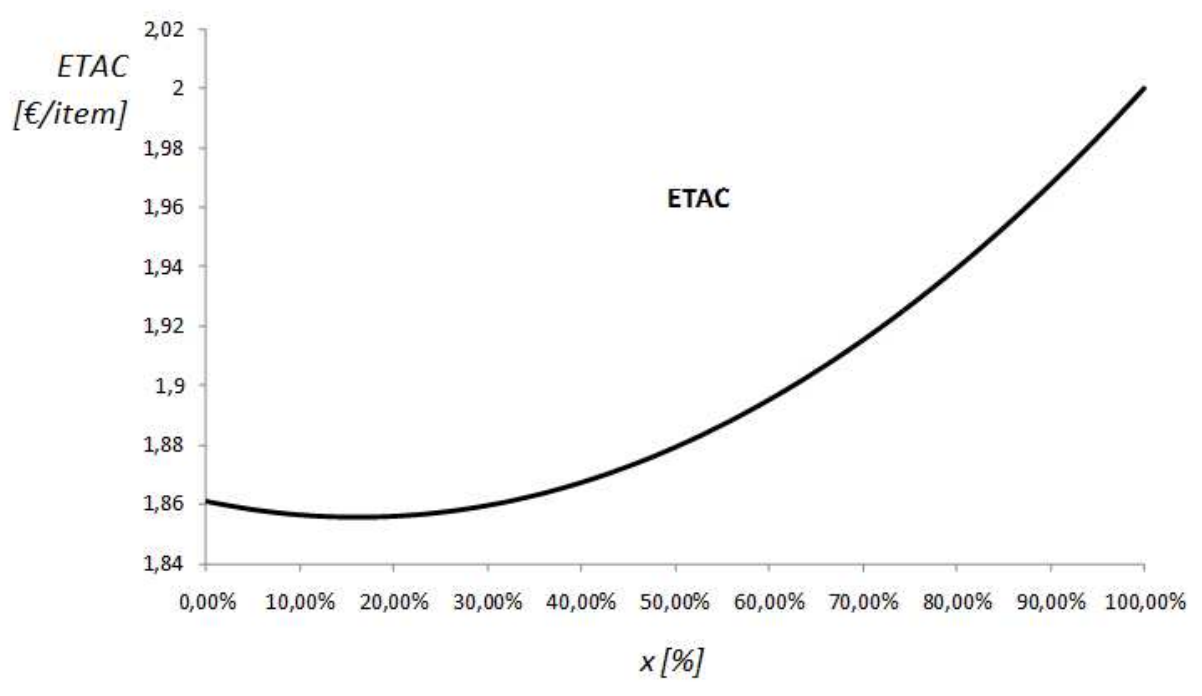

ETAC function over $\mathrm{x}$ for scenario 1 
1

2

3

4

5

6

7

8

9

10

11

12

13

14

15

16

17

18

19

20

21

22

23

24

25

26

27

28

29

30

31

32

33

34

35

36

37

38

39

40

41

42

43

44

45

46

47

48

49

50

51

52

53

54

55

56

57

58

59

60

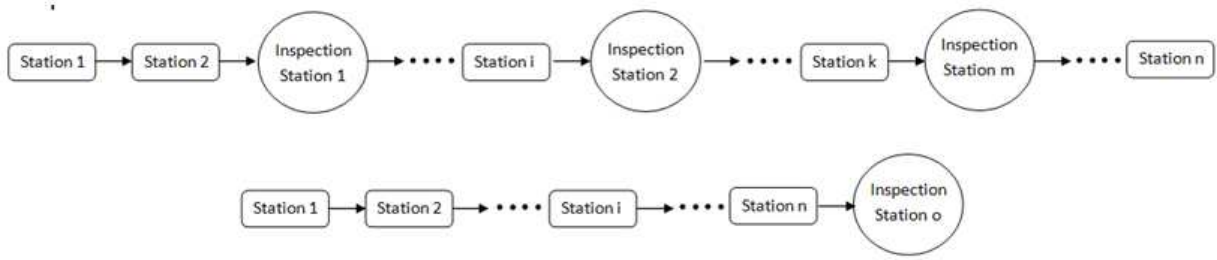

In-Line vs Final Inspection Configuration 


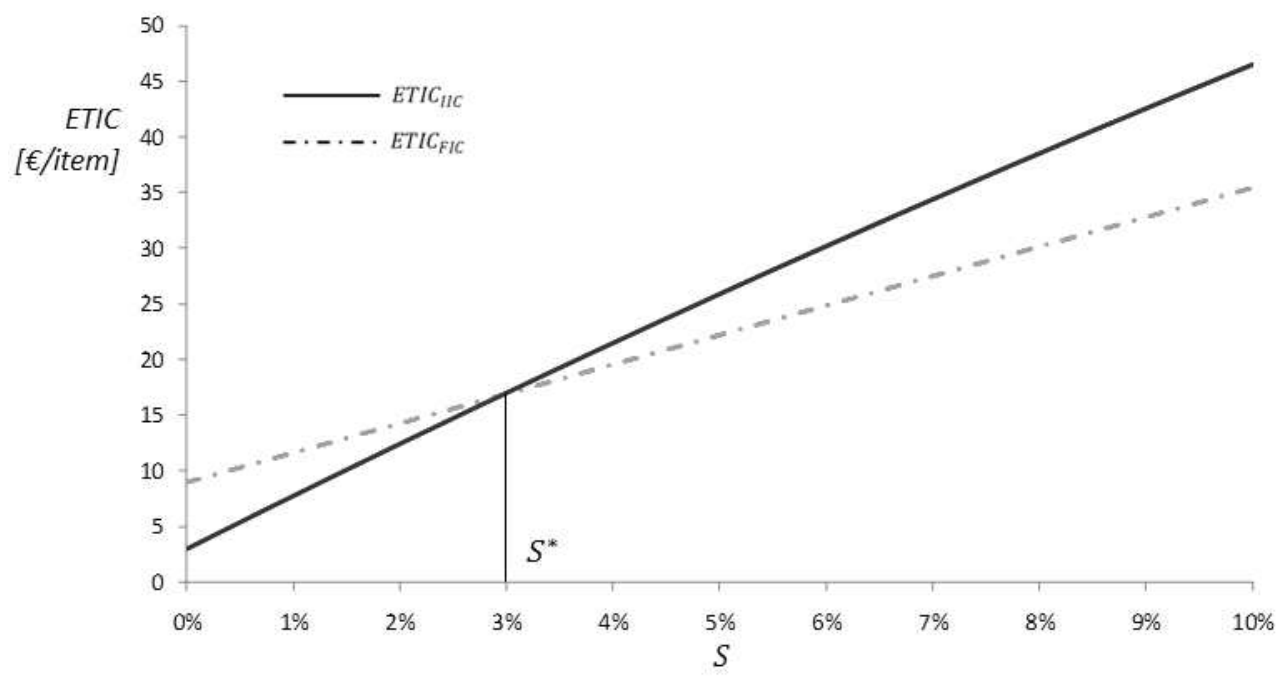

Expected Total Inspection Cost (ETIC) for In-Line vs Final station configuration in function of S 


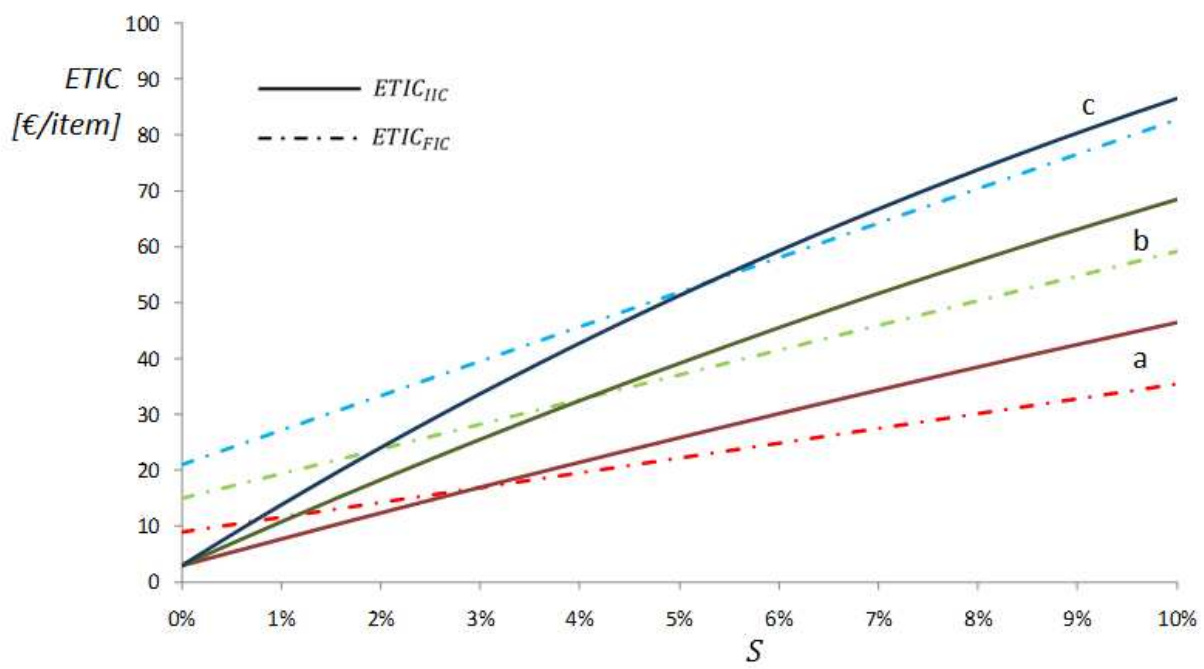

Comparison of ETIC functions varying the number of station $71 \times 37 \mathrm{~mm}(300 \times 300 \mathrm{DPI})$ 


1
2
3
4
5
6
7
8
9
10
11
12
13
14
15
16
17
18
19
20
21
22
23
24
25
26
27
28
29
30
31
32
33
34
35
36
37
38
39
40
41
42
43
44
45
46
47
48
49
50
51
52
53
54
55
56
57
58
60

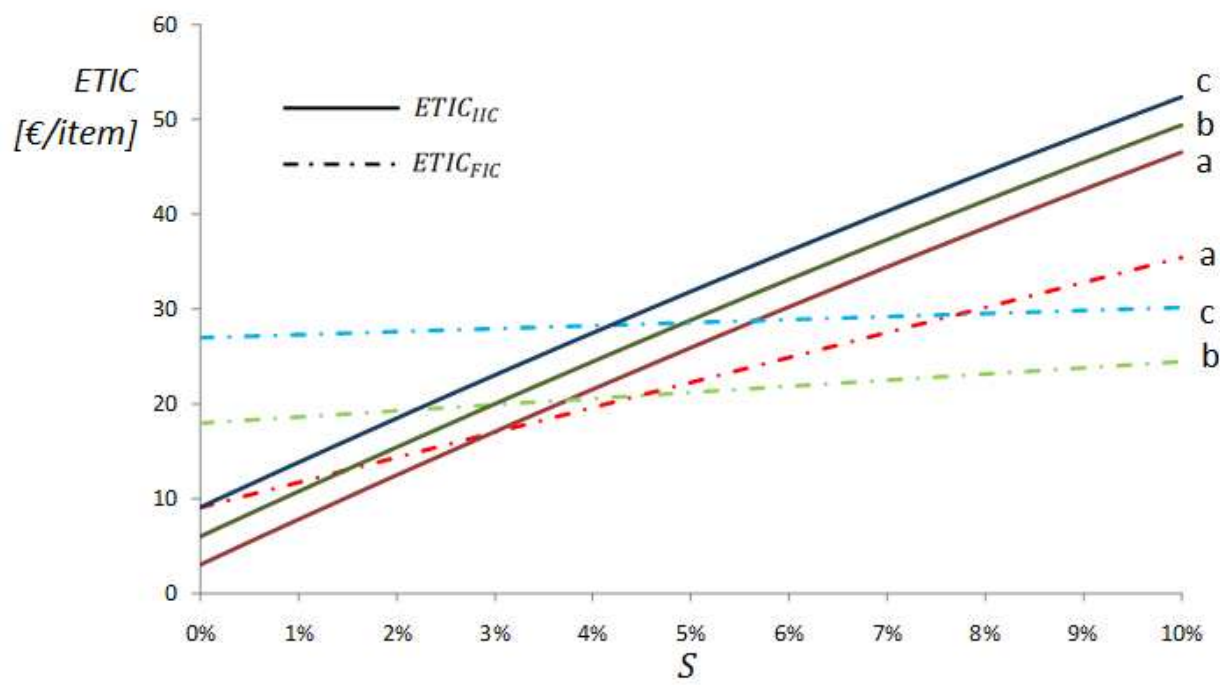

Comparison of ETIC function varying the inspection time control $62 \times 34 \mathrm{~mm}(300 \times 300 \mathrm{DPI})$

http://mc.manuscriptcentral.com/tprs Email: ijpr@lboro.ac.uk 


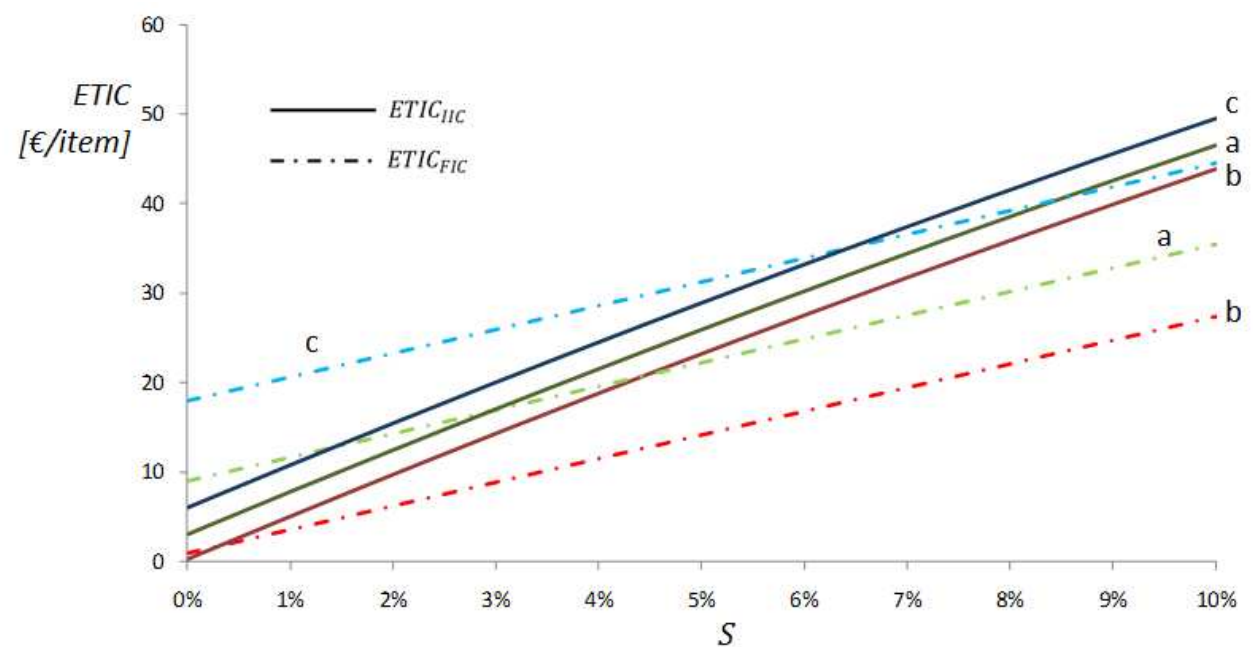

a)

Comparison of ETIC function varying the cost parameters $69 \times 38 \mathrm{~mm}(300 \times 300 \mathrm{DPI})$ 


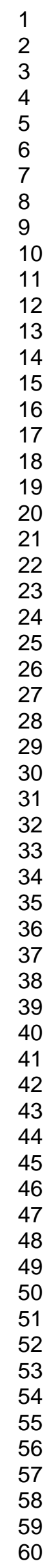

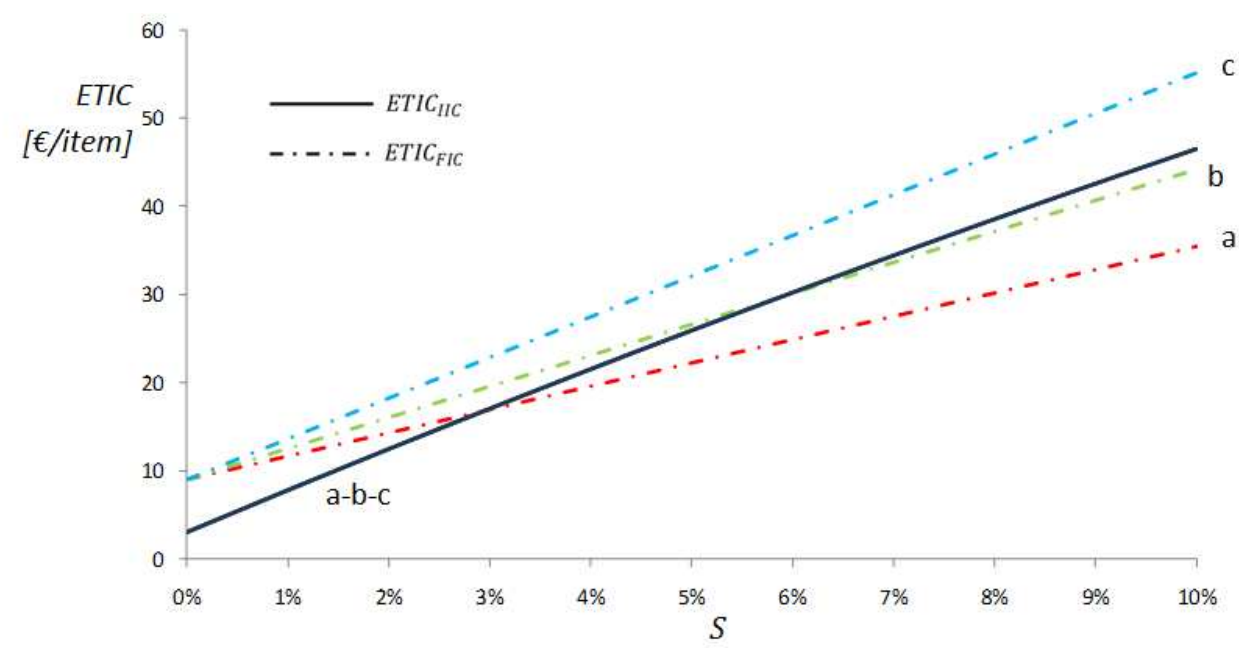

b)

Comparison of ETIC function varying the cost parameters $70 \times 37 \mathrm{~mm}(300 \times 300 \mathrm{DPI})$

http://mc.manuscriptcentral.com/tprs Email: ijpr@lboro.ac.uk 


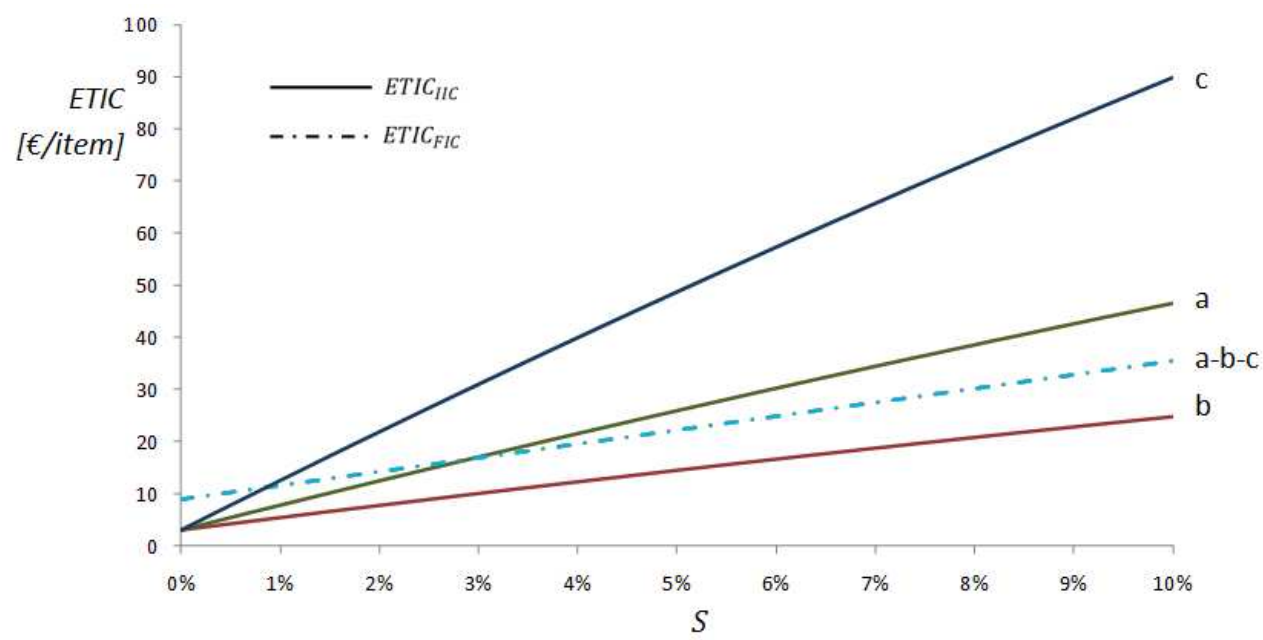

C)

Comparison of ETIC function varying the cost parameters $71 \times 38 \mathrm{~mm}(300 \times 300$ DPI) 


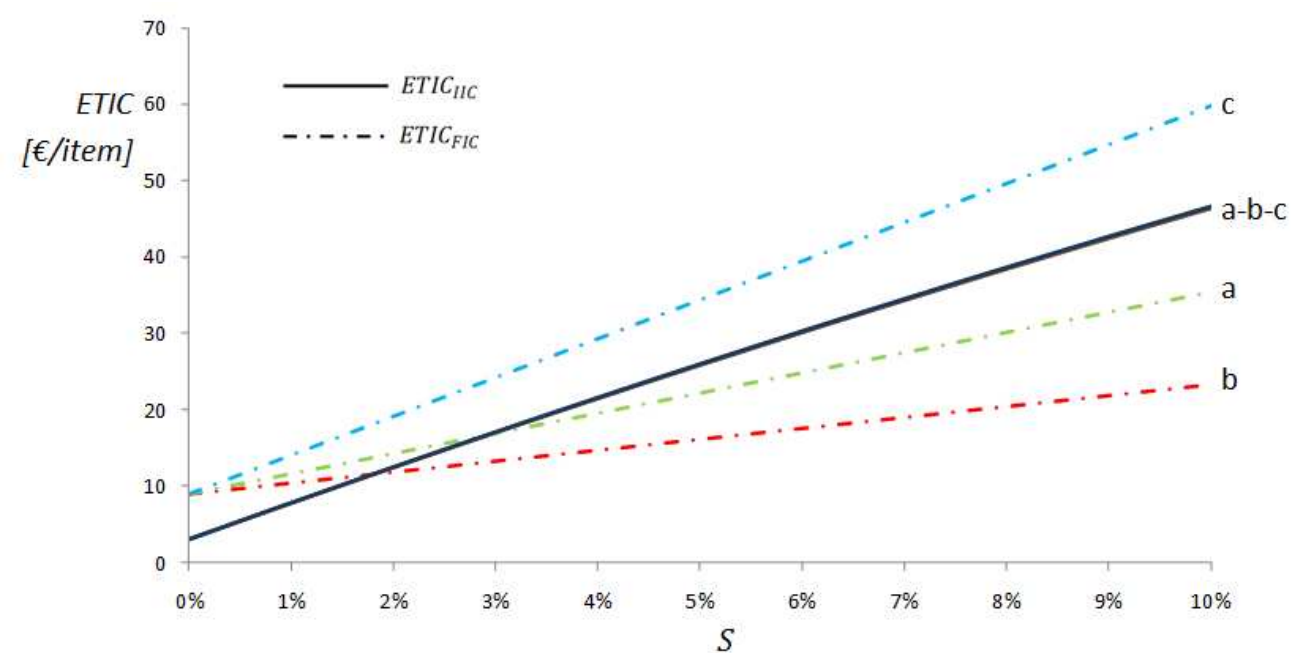

d)

Comparison of ETIC function varying the cost parameters $69 \times 38 \mathrm{~mm}(300 \times 300 \mathrm{DPI})$

http://mc.manuscriptcentral.com/tprs Email: ijpr@lboro.ac.uk 


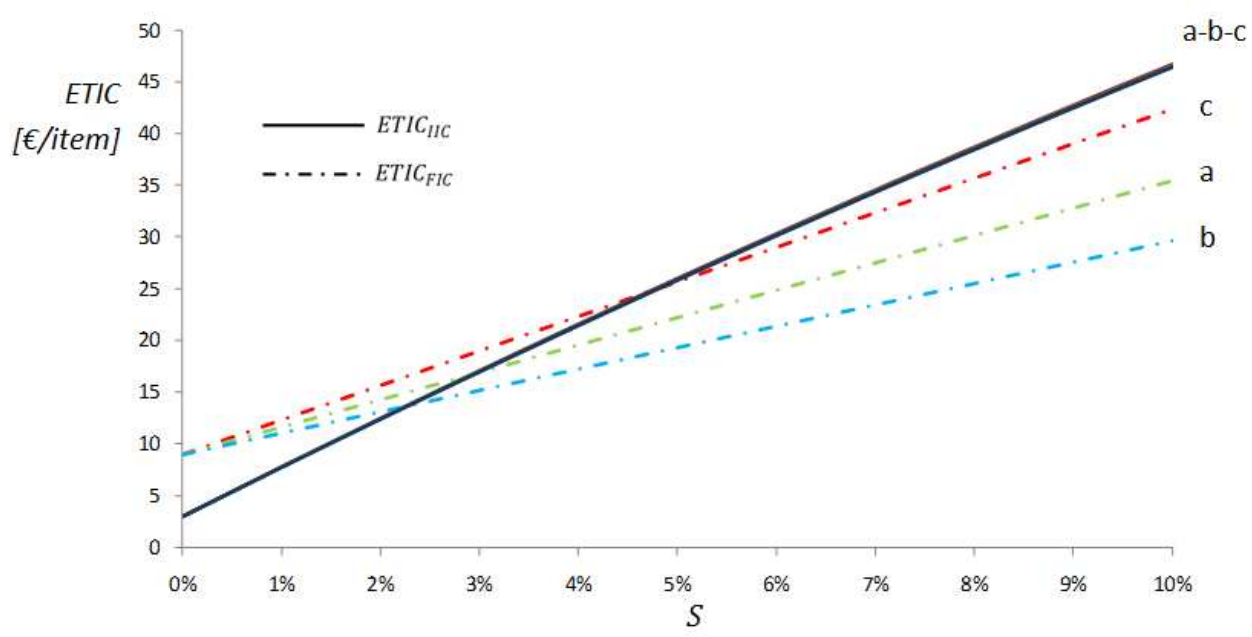

Comparison of ETIC function varying the shape parameter $72 \times 36 \mathrm{~mm}(300 \times 300 \mathrm{DPI})$ 


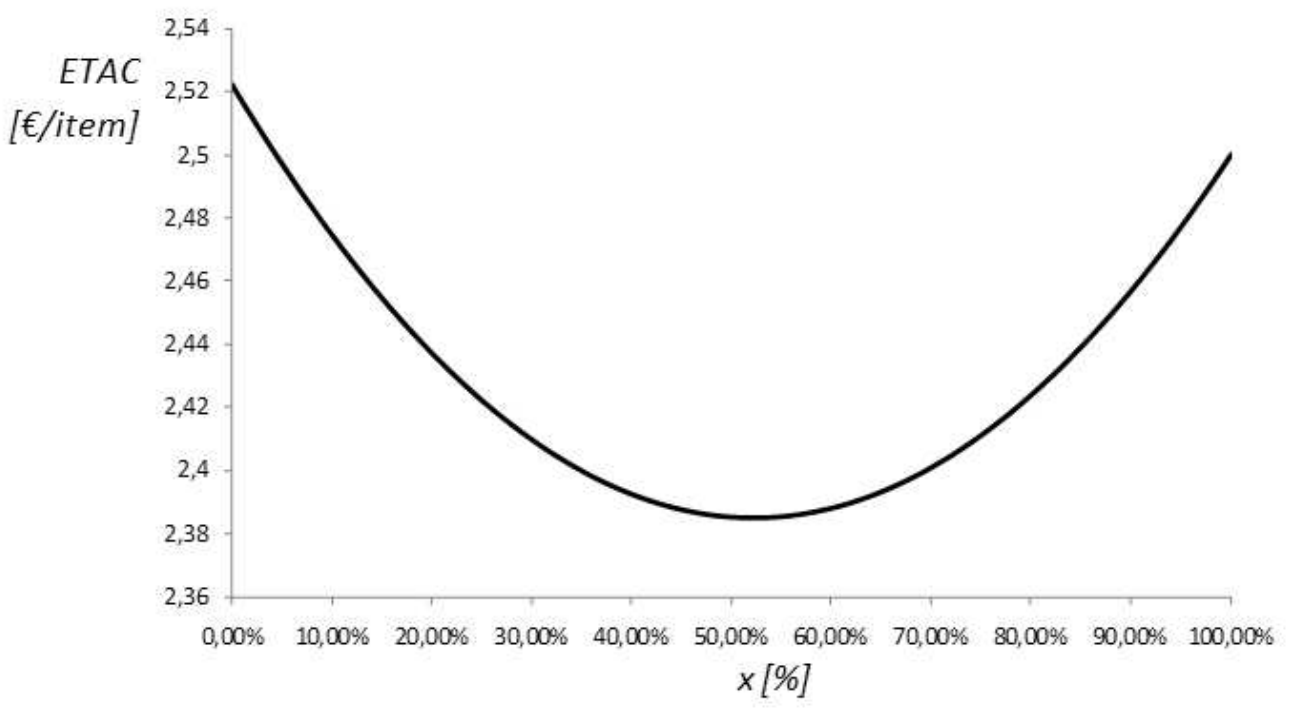

ETAC function for Pump Body 
1

2

3

4

5

6

7

8

9

10

11

12

13

14

15

16

17

18

19

20

21

22

23

24

25

26

27

28

29

30

31

32

33

34

35

36

37

38

39

40

41

42

43

44

45

46

47

48

49

50

51

52

53

54

55

56

57

58

59

60

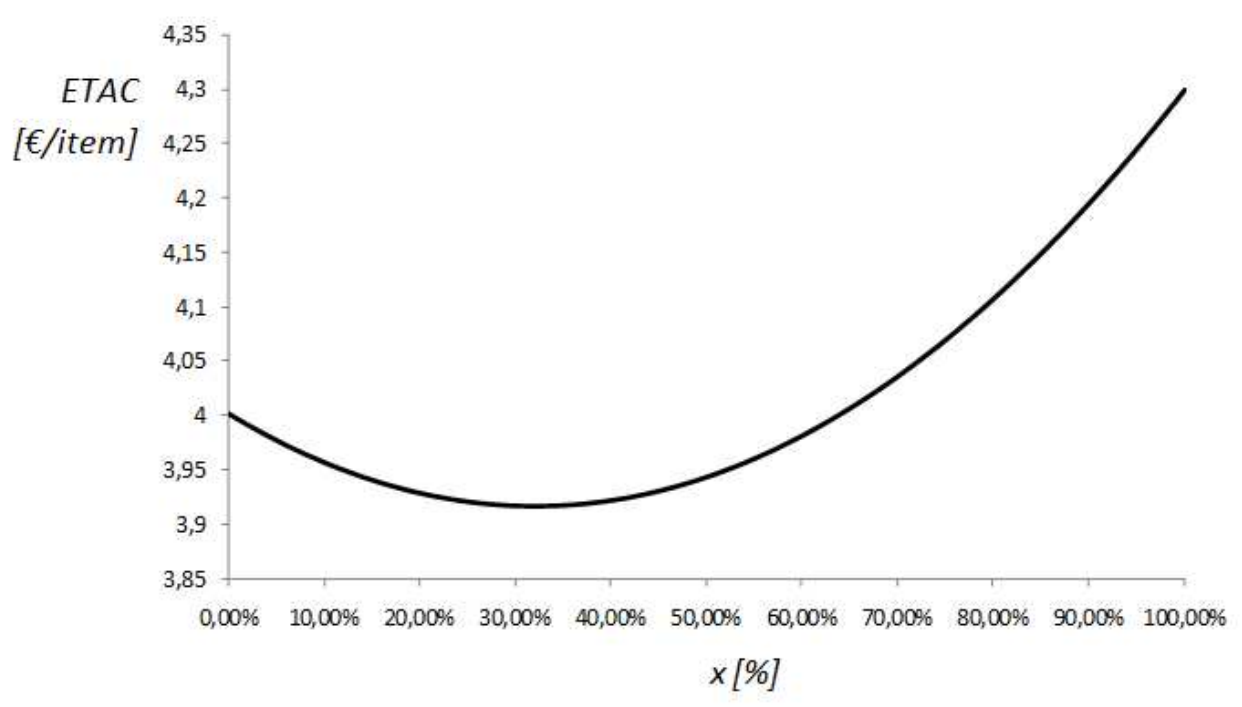

ETAC function for Body Backplate 

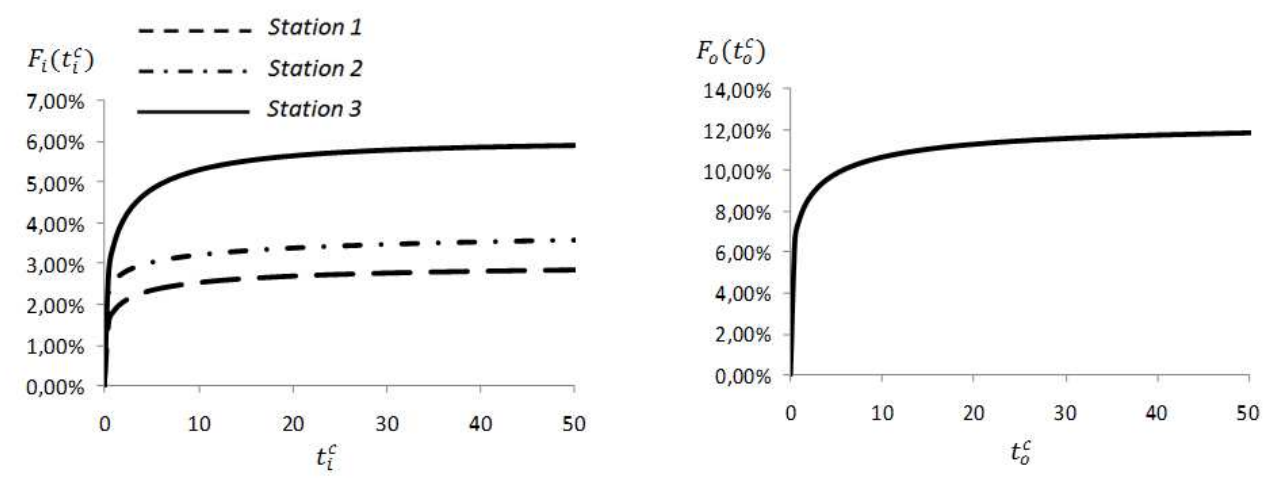

Defect rate in function of inspection time, for station 1, 2 and 3 (left) and final station (right) 


\begin{tabular}{|c|c|c|c|}
\hline Parameters & Scenario 1 & Scenario 2 & Scenario 3 \\
\hline$s$ & $1.80 \%$ & $3.60 \%$ & $0.50 \%$ \\
\hline$C_{u c}$ & 2.00 & 4.00 & 1.00 \\
\hline$C_{u c}^{x}$ & 8.00 & 12.00 & 5.00 \\
\hline$C_{u c}^{r^{x}}$ & 25.00 & 32.00 & 24.00 \\
\hline$N C_{p}$ & $80.00 \%$ & $50.00 \%$ & $20.00 \%$ \\
\hline$N C_{c}$ & $20.00 \%$ & $50.00 \%$ & $80.00 \%$ \\
\hline$C_{p}^{\prime}$ & 60.00 & 85.00 & 70.00 \\
\hline $\mathrm{C}^{\prime \prime} p$ & 210.00 & 240.00 & 180.00 \\
\hline$c_{m}$ & 2.00 & 6.00 & 3.00 \\
\hline$c_{\text {TONG }}$ & 22.80 & 44.00 & 40.40 \\
\hline$C_{A P T}$ & 92.00 & 168.50 & 161.00 \\
\hline$x^{*}$ & $16.18 \%$ & $100.00 \%$ & $0.00 \%$ \\
\hline$C C$ & 0.32 & 4.00 & 0.00 \\
\hline$P C$ & 1.53 & 0.00 & 0.91 \\
\hline$E T A C$ & 1.85 & 4.00 & 0.91 \\
\hline
\end{tabular}

Tab. 1: Numerical example of Acceptance policy 


\section{Scenario}

“BASE"

\begin{tabular}{|c|c|c|}
\hline$n$ & number of inspection stations & 3 \\
\hline$t_{i}^{g}$ and $t_{a}^{g}$ & inspection time at station $i$ equal to the inspection time for final station $o$ & 30.00 \\
\hline$c_{i}^{2 H e}$ and $c_{o}^{20}$ & $\begin{array}{l}\text { inspection unit cost per time at station } i \text { equal to the inspection unit cost } \\
\text { per time at final station } o\end{array}$ & 0.10 \\
\hline$c_{i}^{u s 1}$ & mean unit cost for remove one defect at station $i$ & 8.00 \\
\hline$c_{a}^{2 u s 1}$ & mean unit cost for remove one defect at final station $o$ & 160.00 \\
\hline$c_{i}^{2 u s z}$ & $\begin{array}{l}\text { mean penalty unit cost for a defect occurs after time } t_{i}^{E} \text { at station } i \text { equal } \\
\text { to the mean penalty unit cost for a defect occurs after time } t_{\delta}^{E} \text { at final } \\
\text { station } o\end{array}$ & 900.00 \\
\hline$\alpha_{i}$ & $\begin{array}{l}\text { scale factor of Weibull distribution for components or sub-assembled } \\
\text { tested at station } i\end{array}$ & 10.00 \\
\hline$\beta_{i}$ & $\begin{array}{l}\text { scale factor of Weibull distribution for components or sub-assembled } \\
\text { tested at station } i\end{array}$ & 0.80 \\
\hline
\end{tabular}




\begin{tabular}{|c|c|c|}
\hline Parameters & Pump Body & Body Backplate \\
\hline$s$ & $2.20 \%$ & $3.10 \%$ \\
\hline$C_{w E C}$ & 2.50 & 4.20 \\
\hline$C_{\mathrm{REC}}^{\prime}$ & 22.00 & 26.00 \\
\hline$C_{u \in \mathbb{L}}^{f^{s}}$ & 28.00 & 37.00 \\
\hline$N C_{p}$ & $86.00 \%$ & $64.00 \%$ \\
\hline$N C_{0}$ & $14.00 \%$ & $36.00 \%$ \\
\hline$C_{B}$ & 72.00 & 48.00 \\
\hline$C_{p}^{*}$ & 192.00 & 192.00 \\
\hline$C_{m}$ & 3.00 & 2.50 \\
\hline$C_{\text {UCNe }}$ & 45.68 & 53.52 \\
\hline$C_{A P T}$ & 91.80 & 102.34 \\
\hline$x^{*}$ & $52.20 \%$ & $32.04 \%$ \\
\hline $\mathrm{CC}$ & 1.31 & 1.38 \\
\hline$P C$ & 1.08 & 2.54 \\
\hline $\operatorname{ETAC}\left(x^{*}\right)$ & 2.39 & 3.92 \\
\hline$E T A C(0)$ & 2.52 & 4.00 \\
\hline$\triangle E T A C$ & $-5.43 \%$ & $-2.13 \%$ \\
\hline
\end{tabular}

Tab. 3: Inspection parameters for analyzed components 


\begin{tabular}{|c|c|c|c|c|c|}
\hline \multirow{2}{*}{ Parameters } & \multicolumn{3}{|c|}{ In-Line Inspection Configuration } & \multirow{2}{*}{ Parameters } & \multirow{2}{*}{$\begin{array}{c}\text { Final Station } \\
\text { Configuration }\end{array}$} \\
\hline & Station 1 & Station 2 & Station 3 & & \\
\hline$c_{i}^{u c}$ & $0.01 € / \mathrm{s}$ & $0.01 € / \mathrm{s}$ & $0.01 € / \mathrm{s}$ & $c_{0}^{2 u O}$ & $0.01 € / \mathrm{s}$ \\
\hline$c_{i}^{\text {us }}$ & $1 € /$ item & $2 € /$ item & $1.5 € /$ item & $c_{0}^{2431}$ & $20 € /$ item \\
\hline$c_{1}^{2} \operatorname{rsz}$ & $150 € /$ item & $150 € /$ item & $150 € /$ item & $c_{n}^{u n s}$ & $150 € /$ item \\
\hline$\alpha_{i}$ & 1.2 & 0.9 & 1.5 & & - \\
\hline$\beta_{i}$ & 0.3 & 0.2 & 0.4 & & - \\
\hline$t_{i}^{p}$ & $40 \mathrm{~s}$ & $35 \mathrm{~s}$ & $26 s$ & $t_{n}^{c}$ & $40 \mathrm{~s}$ \\
\hline
\end{tabular}

Tab. 4: Case Study Data

\begin{tabular}{|c|c|c|c|c|c|c|}
\hline & \multicolumn{3}{|c|}{ In-Line Inspection Configuration } & & \multirow{2}{*}{$\begin{array}{l}\text { Final Station } \\
\text { Configuration }\end{array}$} & \multirow{2}{*}{$\begin{array}{l}\text { Initial Scenario } \\
\text { (no inspection) }\end{array}$} \\
\hline & Station 1 & Station 2 & Station 3 & 2 & & \\
\hline$S_{i}$ & $3.000 \%$ & $4.000 \%$ & $6.000 \%$ & $s_{0}$ & $12.467 \%$ & $12.467 \%$ \\
\hline $\left.\mathbb{Z} F_{i}(t]_{i}^{0}\right)$ & $2.829 \%$ & $3.500 \%$ & $5.738 \%$ & $Z_{n}\left(t_{n}^{e}\right)$ & $12.465 \%$ & $0.000 \%$ \\
\hline$s_{i}-\left[F_{i}\left(t_{-i}^{c}\right)\right.$ & $0.171 \%$ & $0.500 \%$ & $0.262 \%$ & $\mathbb{Z} S_{0}-F_{0}\left(t_{-0}^{0}\right)$ & $0.002 \%$ & $12.467 \%$ \\
\hline$c_{i}^{i}$ & 0.400 & 0.350 & 0.260 & $C_{5}^{E}$ & 0.400 & 0.000 \\
\hline$C_{i}^{s 1}$ & 0.028 & 0.070 & 0.086 & $C_{0}^{\sigma 1}$ & 2.493 & 0.000 \\
\hline$C_{i}^{32}$ & 0.257 & 0.750 & 0.393 & $C_{0}^{s 2}$ & 0.003 & 18.701 \\
\hline$C_{i}^{o}+C_{i}^{s 1}+C_{i}^{s 2}$ & 0.685 & 1.170 & 0.740 & & & \\
\hline$E C_{N C}$ & & 2.595 & & $E C_{E I C}$ & 2.896 & 18.701 \\
\hline
\end{tabular}

Tab. 5: Defective parameter and Expected Total Costs 